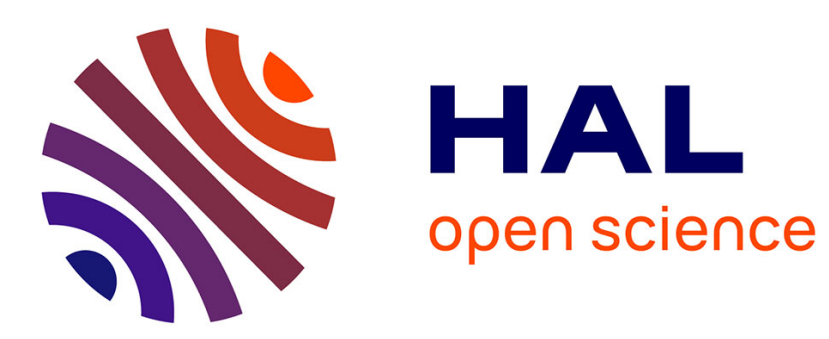

\title{
Mammary pheromone-induced odour learning influences sucking behaviour and milk intake in the newborn rabbit
}

\author{
Mélanie Jouhanneau, Benoist Schaal, Gérard Coureaud
}

\section{To cite this version:}

Mélanie Jouhanneau, Benoist Schaal, Gérard Coureaud. Mammary pheromone-induced odour learning influences sucking behaviour and milk intake in the newborn rabbit. Animal Behaviour, 2016, 111, pp.1-11. 10.1016/j.anbehav.2015.10.003 . hal-01260999

\section{HAL Id: hal-01260999 \\ https://hal.science/hal-01260999}

Submitted on 22 Jan 2016

HAL is a multi-disciplinary open access archive for the deposit and dissemination of scientific research documents, whether they are published or not. The documents may come from teaching and research institutions in France or abroad, or from public or private research centers.
L'archive ouverte pluridisciplinaire HAL, est destinée au dépôt et à la diffusion de documents scientifiques de niveau recherche, publiés ou non, émanant des établissements d'enseignement et de recherche français ou étrangers, des laboratoires publics ou privés. 


\title{
Mammary pheromone-induced odour learning influences sucking behaviour and milk intake in the newborn rabbit
}

\author{
Mélanie Jouhanneau, Benoist Schaal, Gérard Coureaud* \\ Centre des Sciences du Goût et de l'Alimentation, CNRS, INRA, Université de Bourgogne, Dijon, France
}

\section{A R T I C L E I N F O}

\section{Article history:}

Received 3 April 2015

Initial acceptance 21 May 2015

Final acceptance 14 September 2015

Available online 5 November 2015

MS. number: 15-00275R

\section{Keywords:}

conditioning

feeding behaviour

mother-neonate relationship

olfaction

Oryctolagus cuniculus

\begin{abstract}
Newborn rabbits, Oryctolagus cuniculus, locate their mother's nipples through typical orocephalic movements elicited by odour stimuli, in particular by the mammary pheromone (MP). The MP also promotes neonatal odour learning: after single pairing with the MP, an initially neutral odorant becomes able to elicit sucking-related head-searching/oral-grasping movements. However, the behavioural significance of the MP-induced odour learning remains poorly understood. We carried out three experiments to explore its influence on milk intake and compare its consequences with those resulting from nursing-induced conditioning. First, pups conditioned to an odorant by pairing with the MP on postnatal days $2-3$ were shown to gain more milk on day 4 during nursing by a female carrying the conditioned odorant along the nipple lines. Second, surprisingly, nursing-induced odour learning failed to induce this effect. We therefore determined whether the location of the conditioned odorant on or around the nipples modified the pups' milk intake: it appeared that after nursing-induced conditioning, the pups gained more milk when the conditioned odorant was applied directly on the nipples. Moreover, several results showed that pups could learn different odorants during successive days of conditioning, and that the more recently acquired cue was the most influential on milk intake. This study suggests that the MP plays a critical role to ensure sucking performance in newborn rabbits, not only through its releasing effect, but also through its ability to promote the acquisition of novel odours carried by the mother.
\end{abstract}

() 2015 The Association for the Study of Animal Behaviour. Published by Elsevier Ltd. All rights reserved.
The days following birth are decisive for the survival of newborn mammals. They need to rapidly contact the mother and reach her nipples to get nutrients and antibodies carried in colostrum and milk (Blum \& Hammon, 2000; Goursaud \& Nowak, 1999; Xu, 1996). In species bearing altricial newborns, suckling is initiated by the mother but neonates have to locate and orally grasp the nipples by themselves. To that goal, they respond to thermal, tactile and odour stimuli provided by the mother (e.g. Al Aïn, Belin, Schaal, \& Patris, 2013; Larson \& Stein, 1984; Raihani, Gonzalez, Arteaga, \& Hudson, 2009; Schaal, 2010; Teicher \& Blass, 1977; Varendi, Porter, \& Winberg, 1994). In the European rabbit, Oryctolagus cuniculus, lactating females produce two kinds of olfactory stimuli that alter the pups' behaviour: individual-specific cues depending on the physiological state and diet of the female (Bilkó, Altbäcker, \& Hudson, 1994; Coureaud \& Schaal, 2000; Coureaud, Schaal,

\footnotetext{
* Correspondence: G. Coureaud, Centre des Sciences du Goût et de l'Alimentation, UMR 6265 CNRS, 1324 INRA, Université de Bourgogne, F-21000 Dijon, France and, from 2016, Centre de Recherche en Neurosciences de Lyon, UMR 5292 CNRS, U1028 INSERM, Université Lyon 1, F-69366 Lyon, France.

E-mail address: coureaudg@hotmail.fr (G. Coureaud).
}

Hudson, Orgeur, \& Coudert, 2002; Hudson \& Distel, 1982) and species-specific signals emitted by all lactating females of the species (Hudson \& Distel, 1983). Among the latter, a volatile compound isolated from milk, 2-methylbut-2-enal, releases the typical head-searching/oral-grasping movements usually displayed by pups during nursing. This compound, showing pheromonal properties (as defined by Beauchamp, Doty, Moulton, \& Mugford, 1976), has been called the mammary pheromone (MP; Coureaud, 2001; Coureaud, Langlois, Perrier, \& Schaal, 2003; Moncomble et al., 2005; Schaal et al., 2003). Its efficacy in releasing searching-grasping responses in pups is general to O. cuniculus, although it changes during the lactation period. Indeed, both domestic and wild rabbit pups respond to the MP, with the response rates highest during the first 10 postnatal days, progressively decreasing thereafter and completely vanishing at weaning (Coureaud, Rödel, Kurz, \& Schaal, 2008). Some pups (<10\%), however, are unresponsive on postnatal day 1 , which leads to deficient milk intake and high mortality before weaning (especially in low birth weight individuals; Coureaud, Fortun-Lamothe, Langlois, \& Schaal, 2007). In addition to variations in pup responsiveness, the emission of MP in milk is variable during the postpartum period. Indeed, rabbit milk 
contains a higher concentration of MP in early than late lactation (Coureaud, Langlois, Perrier, \& Schaal, 2006). Collectively, these results indicate that the MP is a key releasing signal that controls the interaction of rabbit neonates with the doe.

Nursing provides much more than food to neonates. It also provides the opportunity to learn about the surroundings during reinforcing contacts with the mother and her body, especially during the intake of milk (Brake, 1981; Delaunay-El Allam, Marlier, \& Schaal, 2006; Hepper \& Wells, 2006; Johanson \& Hall, 1979). Conditioning that occurs during nursing has consequences for the next sucking episodes (Cheslock, Varlinskaya, Petrov, \& Spear, 2000; Miller \& Spear, 2008; Pedersen, Williams, \& Blass, 1982) and also for food or sexual preferences later during development (Fillion \& Blass, 1986; Galef \& Henderson, 1972). Newborn rabbits are able to learn novel odour cues during the first nursing episodes (Allingham, Brennan, Distel, \& Hudson, 1999; Bilkó et al., 1994; Coureaud, Moncomble, et al., 2006; Hudson, 1985; Hudson, Labra-Cardero, \& Mendoza-Soylovna, 2002; Ivanitskii, 1958; Kindermann, Gervais, \& Hudson, 1991; Serra, Ferreira, Mirabito, Levy, \& Nowak, 2009). They need only a single exposure to an artificial odorant painted on the mother's abdomen just before nursing; when the same odorant is presented again $24 \mathrm{~h}$ later, it triggers the head-searching movements that are typically usually released by the female's abdomen or her milk. Among the reinforcing events that occur during nursing, tactile or thermal properties of the maternal fur, expression of searching or sucking actions, milk intake, gastric filling or postabsorptive events linked to satiation have been considered (Hudson et al., 2002; Serra et al., 2009). An additional reinforcing factor is the MP itself, which functions as an extremely efficient promoter of odour learning. Thus, after single and simultaneous exposure to an initially neutral odorant paired with the MP (in the absence of the mother), rabbit pups exhibit a strong searching - grasping response when later exposed to the odorant alone (Charra, Datiche, Gigot, Schaal, \& Coureaud, 2013; Coureaud, Languille, Schaal, \& Hars, 2009; Coureaud, Moncomble, et al., 2006; Patris, Perrier, Schaal, \& Coureaud, 2008). The response induced after conditioning with the MP is maximal $24 \mathrm{~h}$ after the pairing (i.e. when the next nursing happens) and is similar to that resulting from nursing-induced conditioning (Coureaud, Moncomble, et al., 2006). Moreover, the MP allows pups to learn a mixture of several odorants during a single conditioning session, or distinct odorants encountered during successive conditionings (e.g. Coureaud, Hamdani, Schaal, \& Thomas-Danguin, 2009; Coureaud, Thomas-Danguin, Le Berre, \& Schaal, 2008; Coureaud, Thomas-Danguin, Wilson, \& Ferreira, 2014; Romagny, ThomasDanguin, \& Coureaud, 2015; Sinding et al., 2013; Sinding, Thomas-Danguin, Crepeaux, Schaal, \& Coureaud, 2011). In other words, the MP is not only a releaser of nipple-search behaviour but also a potent reinforcing agent for neonatal odour learning.

To date, the influence of MP-induced odour learning on neonatal behaviour has not been studied in the natural context of interaction with the mother. One may suggest that it facilitates the acquisition of odour cues carried on the maternal abdomen on one day, which could improve the responsiveness of pups to the mother on the next day, ending in better nipple location and sucking performance. Such a mechanism would be particularly adaptive in the rabbit since nursing occurs only once per day for less than 5 min (Zarrow, Denenberg, \& Anderson, 1965) and neonatal survival directly depends on sucking success during the very first nursing episodes (Coureaud et al., 2000). Here, we investigated the influence of MPinduced learning of an odorant on neonates in terms of ability to obtain milk (Experiment 1) and compared this influence with that created by nursing-induced learning (Experiment 2). We also evaluated whether the site where the conditioned odorant is applied on the maternal abdomen (nipple versus non-nipple areas) influenced nipple location by rabbit pups and milk intake (Experiment 3). We hypothesized that both MP-induced and nursing-induced odour learning will positively influence the neonatal ability to find the nipples and suck, and that this effect would be maximal when the conditioned odorant is restricted to the nipples themselves.

\section{GENERAL METHODS}

\section{Animals, Breeding and Housing Conditions}

New Zealand rabbits (Charles River Strain, France) were housed in the breeding unit of the Centre de Zootechnie (Université de Bourgogne, Dijon). Females and males were kept in individual cages (74 $\times 72 \mathrm{~cm}$ and $42 \mathrm{~cm}$ high and $64 \times 60 \mathrm{~cm}$ and $35 \mathrm{~cm}$ high, respectively for females and males). For pregnant does, a nestbox $(39 \times 25 \mathrm{~cm}$ and $32 \mathrm{~cm}$ high) was added to the outside of the cages 2 days before the day of birth (day 0 ). To equalize the nursing experience of the pups, the females were allowed to enter the nest once per day for 15 min to nurse (at 1130 hours; see Ethical Note). Animals were kept under a constant 12:12 h light:dark cycle (light on at 0700 hours) and ambient air temperature was maintained at $19-21^{\circ} \mathrm{C}$. Water and pellet food (Lapin Elevage 110, Safe, France) were provided ad libitum.

A total of 242 pups born from 42 females were used. On postnatal day 1, $3 \mathrm{~h}$ after nursing, the pups were individually weighed (Sartorius, Palaiseau, France; accuracy: $0.1 \mathrm{~g}$ ) and marked on their back. In each litter, the six pups presenting the most homogeneous weight and for which milk intake was confirmed (by screening of gastric content through the transparent abdominal skin; e.g. Coureaud et al., 2000) were selected as experimental animals. The remaining pups were left in the litter (if $<8$ ) or adopted (if $>8$ ) in other litters which were not used for the present study.

\section{Stimuli}

The MP (2-methylbut-2-enal) was used as the unconditioned stimulus. Ethyl acetoacetate (E) and limonene (L) constituted the conditioned and/or control stimuli. These odorants were chosen because they spontaneously elicit only sniffing in newborn rabbits (Coureaud, Languille, et al., 2009; Coureaud, Moncomble, et al., 2006). The odorants and the E+MP or L+MP mixtures (50/50 v/v ratio) were prepared in distilled water at a final concentration of $10^{-5} \mathrm{~g} / \mathrm{ml}$ (an efficient level for MP-induced conditioning; Coureaud, Moncomble, et al., 2006). All the odorants were purchased from Aldrich (Saint-Quentin-Fallavier, France).

\section{Odour-learning Procedures}

Two methods were used to induce odour learning in pups, one using the reinforcing properties of the MP (experiment 1 ) and the other based on the multimodal reinforcing context formed by the nursing situation (including the MP naturally emitted in milk) (Experiments 2 and 3). Both were repeated on postnatal days 2 and 3 to optimize the acquisition of the learned odorant.

The MP-induced odour learning procedure was carried out following a procedure described in previous studies (e.g. Charra et al., 2013; Coureaud, Moncomble, et al., 2006; Coureaud et al., 2014; Sinding et al., 2013): 1-2 h before the scheduled nursing time (i.e. between 0930 and 1030 hours), the pups were transferred from the nest to another room of the breeding unit, in a box maintained at ambient temperature. They were then exposed to a cotton pad $(19 \times 14 \mathrm{~cm}$; Fig. 1$)$ scented with $6 \mathrm{ml}$ of either the $\mathrm{E}+\mathrm{MP}$ mixture (group $\mathrm{E}_{\mathrm{MP}} ; N=43$ pups), the $\mathrm{L}+\mathrm{MP}$ mixture (group $\mathrm{L}_{\mathrm{MP}}$; $N=38$ ) or water (control group $\mathrm{W} ; N=18$ ). This odour pad was held 


\begin{tabular}{|c|c|c|}
\hline $\begin{array}{c}\text { Days 2-3 } \\
\text { Conditioning }\end{array}$ & $\begin{array}{l}\text { Days } 4-5 \\
\text { Oral activation test }\end{array}$ & $\begin{array}{c}\text { Days } 4-5 \\
\text { Odorized nursing }\end{array}$ \\
\hline MP-induced & & 378 \\
\hline
\end{tabular}
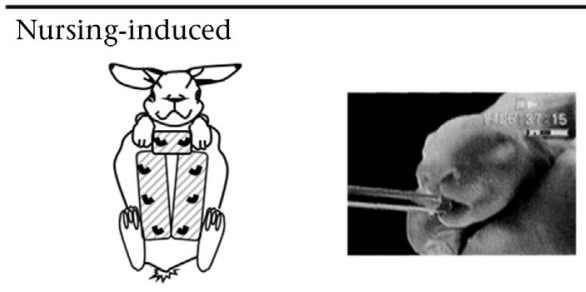

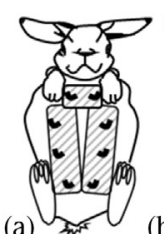

(a)

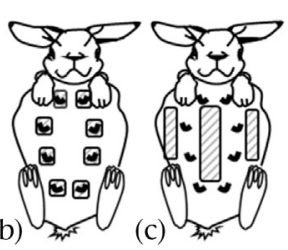

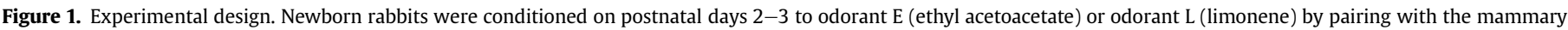

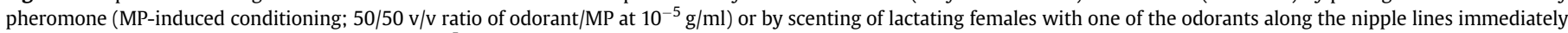

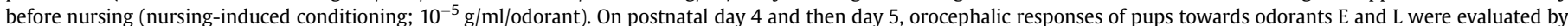

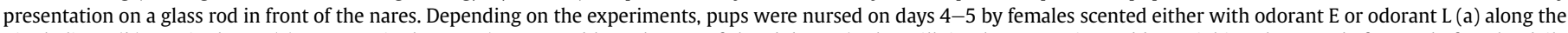

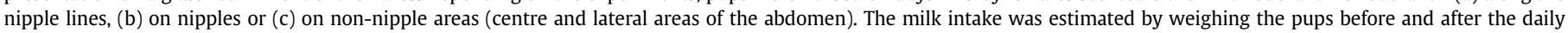
odorized nursing.

for $5 \mathrm{~min}$ at $2 \mathrm{~cm}$ over the pups (six pups per session). Immediately after this exposure, the pups were returned to their nest.

The nursing-induced odour learning was adapted from previous studies (Coureaud, Moncomble, et al., 2006; Hudson, 1985; Ivanitskii, 1958; Kindermann et al., 1991; Patris et al., 2008): the pups were exposed during the daily nursing to the initially neutral odorant $\mathrm{L}\left(\mathrm{L}_{\mathrm{N}} ; N=143\right)$ which was applied immediately before nursing along the nipple lines of their mother (nipples + surrounding fur; Fig. 1), by gently rubbing the doe for $2 \times 30 \mathrm{~s}$ (with $10 \mathrm{~s}$ between sessions) with a cotton pad (same as above) scented with $6 \mathrm{ml}$ of solution. After this abdominal scenting treatment, the female entered the nest within seconds and nursed for 4-5 min (as is usual in the European rabbit; Zarrow et al., 1965). To balance the amount of handling of nursing-induced conditioned neonates with neonates conditioned by pairing with the MP, the pups were transferred from the nest to another room of the breeding unit $1-2 \mathrm{~h}$ before the odorized nursing, and exposed to a pad scented with $6 \mathrm{ml}$ of water (same conditions as above).

\section{Behavioural Test}

The behavioural assay consisted of an orocephalic activation test (e.g. Charra et al., 2013; Coureaud, Moncomble, et al., 2006; Coureaud et al., 2002, 2014; Romagny et al. 2015; Schaal et al., 2003; Sinding et al., 2011) during which each pup was individually immobilized in one gloved hand of the experimenter, its head being left free (Fig. 1). The stimulus was then presented for $10 \mathrm{~s}$ with a glass rod positioned $0.5 \mathrm{~cm}$ in front of the nares. The test was considered positive (i.e. the conditioning was successful) when the odorant elicited head-searching movements (vigorous, lowamplitude horizontal and vertical scanning actions of the head, displayed after stretching of the neck towards the rod) eventually followed by oral grasping of the glass rod extremity. Pups were considered to be nonresponsive when they displayed only sniffing. Each pup from a litter was consecutively tested for its responsiveness to odorants $\mathrm{E}$ and $\mathrm{L}$ (intertrial interval: $120 \mathrm{~s}$ ). The experimenter did not know the treatment group to which the pups belonged. The order of stimuli presentation was counterbalanced from one pup to another. If a pup responded to a stimulus, its muzzle was softly dried with absorbent paper before applying the next stimulation.

Behavioural testing was always run in the morning, $1 \mathrm{~h}$ before the daily nursing, to equalize the pups' motivational state and limit the impact of satiation on their responsiveness (Montigny, Coureaud, \& Schaal, 2006). It was performed on postnatal day 4, i.e. 48 and $24 \mathrm{~h}$ after the first and second conditioning sessions, respectively, and then on day $5,24 \mathrm{~h}$ after the day 4 nursing. This testing was intended to determine (1) whether the pups had efficiently learned the conditioned odorant and whether they retained it $24 \mathrm{~h}$ after the last conditioning episode, (2) whether their retention of the conditioned odour was maintained $48 \mathrm{~h}$ later despite an intermediate nursing episode, and (3) whether the odour learning was selective after the initial learning episodes and remained so after exposure to a congruent or incongruent odour during nursing.

\section{Scented Nursing and Neonatal Milk Intake}

The intake of milk was measured indirectly. To that aim, the pups were first weighed on the morning of days 4 and $5,1 \mathrm{~h}$ before the controlled nursing (weight A; the behavioural assay followed this weighing). Then, immediately before nursing, each female's abdomen was scented with either odorant E, odorant L or water. The odour solution was applied either along the nipple lines, including nipples and their immediately $(2 \mathrm{~cm})$ surrounding fur (Fig. 1a; Experiments 1 and 2), on nipples only (Fig. 1b; Experiment 3 ), or on central and lateral areas of the abdomen that do not harbour nipples (Fig. 1c; Experiment 3). The pups were subsequently nursed in one of these odour and location conditions. Fifteen minutes after nursing (i.e. after the postnursing urination period; Hudson \& Distel, 1982), pups were weighed again (weight B). The individual weight gain of pups during the nursing episode (sucking success) was calculated by subtracting the pups' weight after (weight B) and before suckling (weight A), and by integrating the actual body mass of a pup as a covariate. Thus, the variable submitted to analysis was the daily weight gain relative to the body 
mass (computed as ((weight B - weight A)/weight A) $\times 100$; in $\%$ of body mass) (Coureaud et al., 2000, 2002). The weighing was carried out by two experimenters. Experimenter 1 handed the pups to Experimenter 2 (who was unaware of the treatment groups) who weighed them, and reported the weights to Experimenter 1.

\section{Statistical Analyses}

The proportions of pups eliciting head-searching (and eventually oral-grasping) movements in response to the stimuli during the behavioural assay were compared using the Pearson chi-square test when the pups were conditioned differently but tested for their responsiveness to the same stimulus (independent groups) or the McNemar's chi-square test when they were conditioned similarly and tested for their responsiveness to distinct stimuli (dependent groups). Odds ratios (OR) were calculated, when possible, from $2 \times 2$ contingency tables to evaluate the magnitude of differences in pups' responses between conditions. An OR close to 1 indicates that the response is similar between two groups.

After testing normality (Shapiro-Wilk test) and homoscedasticity (Levene's test), the differences in weight gain (mean $\pm \mathrm{SE}$ ) were compared between groups of pups depending on the mode of conditioning, nature of the conditioned odorant and location of the odorant on the female's abdomen, using the Student's $t$ test when two treatment groups were compared, or one-way analysis of variance (ANOVA) when more than two treatment groups were compared. A significant effect revealed by the ANOVA was further explored using the post hoc Dunnett's test to compare the treatment groups with the control group.

In experiments in which differences existed between the groups, and when the number of pups allowed us to test it, no litter effect appeared in the groups, in either the behavioural orocephalic test (generalized estimating equations modelling of binomial data: from $\chi_{3}^{2}<3.02$ to $\left.\chi_{14}^{2}<22, P>0.05\right)$ or the weight gain measurement (Kruskal-Wallis tests: from $H_{2,20}<0.83$ to $H_{3,24}<6.41$, $P>0.05$ ). Accordingly, the effects observed in the experiments presented here may clearly be regarded as being due to individual pups rather than to the litter from which they originated.

Data were regarded as significant and exact $P$ values are given when the tests (two-tailed) ended in $P<0.05$ (except for $P<0.0001$; Statistica, StatSoft, Tulsa, OK, U.S.A.).

\section{Ethical Note}

In all experiments, the ASAB/ABS and the local, institutional and national rules concerning the care and use of animal subjects have been strictly followed. The experiments were carried out under licence from the CNRS, INRA and French Ministries of Higher Education \& Research and of Agriculture, and after acceptance by the Ethical Committee for Animal Experimentation of the University of Burgundy (Dijon, France; authorization no. 2306). The control of nest access follows the usual practice in rabbit breeding. It mimics the once per day nursing rhythm observed in the wild (Zarrow et al., 1965), and has been shown to improve pup welfare and survival compared with permanent opening of the nest (e.g. Coureaud et al., 2000; Verga, Canali, Pizzi, \& Crimella, 1986). The timing of the experiments, and the experiments themselves, did not disturb the usual nursing schedule of the pups. The scenting of the females was brief and done in the lordosis position to avoid any stress due to imposed supination. For weighing, conditioning and testing, newborns were briefly isolated $(<10 \mathrm{~min})$ in a box maintained at ambient temperature in an experimental room immediately adjacent to the breeding room. Immediately after handling, they were returned to their respective nests.

\section{EXPERIMENT 1: INFLUENCE OF MP-INDUCED ODOUR LEARNING}

\section{Methods}

To evaluate whether MP-induced odour learning influences milk intake in newborn rabbits over the next few days, 43 and 38 pups were conditioned on postnatal days 2 and 3 to odorant $\mathrm{E}$ or $\mathrm{L}$ through pairing with the MP (groups $\mathrm{E}_{\mathrm{MP}}$ and $\mathrm{L}_{\mathrm{MP}}$, respectively). A control group of 18 pups was exposed to water (group W) in the same period. To assess the pups' nursing performance on day $4, \mathrm{~W}$ pups were nursed by unscented females treated only with water, while $\mathrm{E}_{\mathrm{MP}}$ and $\mathrm{L}_{\mathrm{MP}}$ pups were nursed by females scented along the nipple lines with odorant $\mathrm{E}$ (groups $\mathrm{E}_{\mathrm{MP}} / \mathrm{E}$ and $\mathrm{L}_{\mathrm{MP}} / \mathrm{E}, N=22$ and 19 , respectively) or with odorant $\mathrm{L}$ (groups $\mathrm{E}_{\mathrm{MP}} / \mathrm{L}$ and $\mathrm{L}_{\mathrm{MP}} / \mathrm{L}, N=21$ and 19 , respectively). Then, the same groups of pups were also followed up on day 5 for odour responsiveness and postnursing weight gain.

\section{Results}

When tested for a searching response on day 4 before nursing, W pups did not respond (Fig. 2a) but $\mathrm{E}_{\mathrm{MP}}$ pups responded strongly and selectively to odorant $\mathrm{E}$ (McNemar's chi-square test: $\chi_{1}^{2}=34.03, \quad P<0.0001$; Fig. 2 b) while $L_{M P}$ pups responded massively and selectively to odorant L (McNemar's chi-square test: $\chi_{1}^{2}=34.03, P<0.0001$; Fig. 2c). Regarding the weight gain, clear contrasts appeared within the conditioned groups between those exposed to the previously learned odorant and those exposed to the unfamiliar odorant. Thus, pups conditioned to odorant $\mathrm{E}$ and exposed to $\mathrm{E}$ during nursing $\left(\mathrm{E}_{\mathrm{MP}} / \mathrm{E}\right)$ ingested more milk than pups conditioned to $\mathrm{E}$ and exposed to $\mathrm{L}\left(\mathrm{E}_{\mathrm{MP}} / \mathrm{L} ; 18.87 \pm 1.59 \%\right.$ versus $10.78 \pm 0.97 \%$; Student's $t$ test: $t_{41}=4.30, P<0.001$; Fig. 2 e). Similar results were observed in pups conditioned to odorant $\mathrm{L}$ and exposed to $\mathrm{L}$ or to $\mathrm{E}\left(\mathrm{L}_{\mathrm{MP}} / \mathrm{L}\right.$ versus $\mathrm{L}_{\mathrm{MP}} / \mathrm{E}$ : $18.06 \pm 0.94 \%$ versus $13.93 \pm 1.38 \%$; Student's $t$ test: $t_{36}=-2.47, P=0.02$; Fig. 2f). Moreover, the comparison between our five groups, including the control group W $(11.48 \pm 1.37 \%$; Fig. $2 \mathrm{~d})$, revealed differences between some of the conditioned groups and the control group (oneway ANOVA: $F_{4,94}=8.48, P<0.0001$ ): the weight gain was higher in groups $\mathrm{E}_{\mathrm{MP}} / \mathrm{E}$ and $\mathrm{L}_{\mathrm{MP}} / \mathrm{L}$ than in group $\mathrm{W}$ (post hoc Dunnett's test: $P=0.0004$ and $P=0.003$, respectively) while it was similar in groups $\mathrm{E}_{\mathrm{MP}} / \mathrm{L}$ and $\mathrm{L}_{\mathrm{MP}} / \mathrm{E}$ compared to group W (post hoc Dunnett's test: $P=0.99$ and $P=0.52$, respectively). Thus, odorants $E$ and $L$ encountered for the first time by neonates during contact with the maternal abdomen on day 4 were as neutral as the control stimulus (water) and they did not influence milk intake. In contrast, when these odorants were paired with the MP on the previous days, their perception in the context of nursing improved the pups' sucking performance.

On postnatal day 5, $\mathrm{E}_{\mathrm{MP}}$ pups that were nursed by females scented with $\mathrm{E}$ on day 4 (group $\mathrm{E}_{\mathrm{MP}} / \mathrm{E}_{\mathrm{N}}$ ) continued to selectively respond to odorant $\mathrm{E}$ but not to odorant $\mathrm{L}$ (McNemar's chi-square test: $\chi^{2}{ }_{1}=16.1, P<0.001, \mathrm{OR}=19$; Fig. $3 \mathrm{a}$ ), while the subgroup of $\mathrm{E}_{\mathrm{MP}}$ pups nursed by females odorized with L on day 4 (group $\mathrm{E}_{\mathrm{MP}}$ / $\mathrm{L}_{\mathrm{N}}$ ) responded equally to odorants $\mathrm{E}$ and $\mathrm{L}$ (McNemar's chi-square test: $\chi^{2}{ }_{1}=0.17, P>0.05$, OR $=1$; Fig. $\left.3 \mathrm{a}\right) ; \mathrm{E}_{\mathrm{MP}} / \mathrm{L}_{\mathrm{N}}$ pups responded then to odorant $\mathrm{E}$ as much as $\mathrm{E}_{\mathrm{MP}} / \mathrm{E}_{\mathrm{N}}$ pups but more to odorant $\mathrm{L}$ (Pearson chi-square test: $\chi^{2}{ }_{1}=0.73, P=0.39, \mathrm{OR}=1.1$; McNemar's chi-square test: $\left.\chi^{2}{ }_{1}=23.07, P<0.0001, \mathrm{OR}=16.8\right)$. Reciprocally, $\mathrm{L}_{\mathrm{MP}}$ pups nursed by females scented with $\mathrm{L}$ or with $\mathrm{E}$ on day 4 (groups $\mathrm{L}_{\mathrm{MP}} / \mathrm{L}_{\mathrm{N}}$ and $\mathrm{L}_{\mathrm{MP}} / \mathrm{E}_{\mathrm{N}}$ ) displayed high and similar responsiveness to L on day 5 (Pearson chi-square test: $\chi^{2}{ }_{1}=0.23, P>0.05$, $\mathrm{OR}=0.9$; Fig. $3 \mathrm{~b}$ ), whereas only $\mathrm{L}_{\mathrm{MP}} / \mathrm{E}_{\mathrm{N}}$ neonates responded to $\mathrm{E}$ (Pearson chi-square test: $\chi^{2}{ }_{1}=30.8, P<0.0001$ ) and therefore similarly to $\mathrm{E}$ and $\mathrm{L}$ (McNemar's chi-square test: $\chi^{2}{ }_{1}=0.5, P>0.05$, 

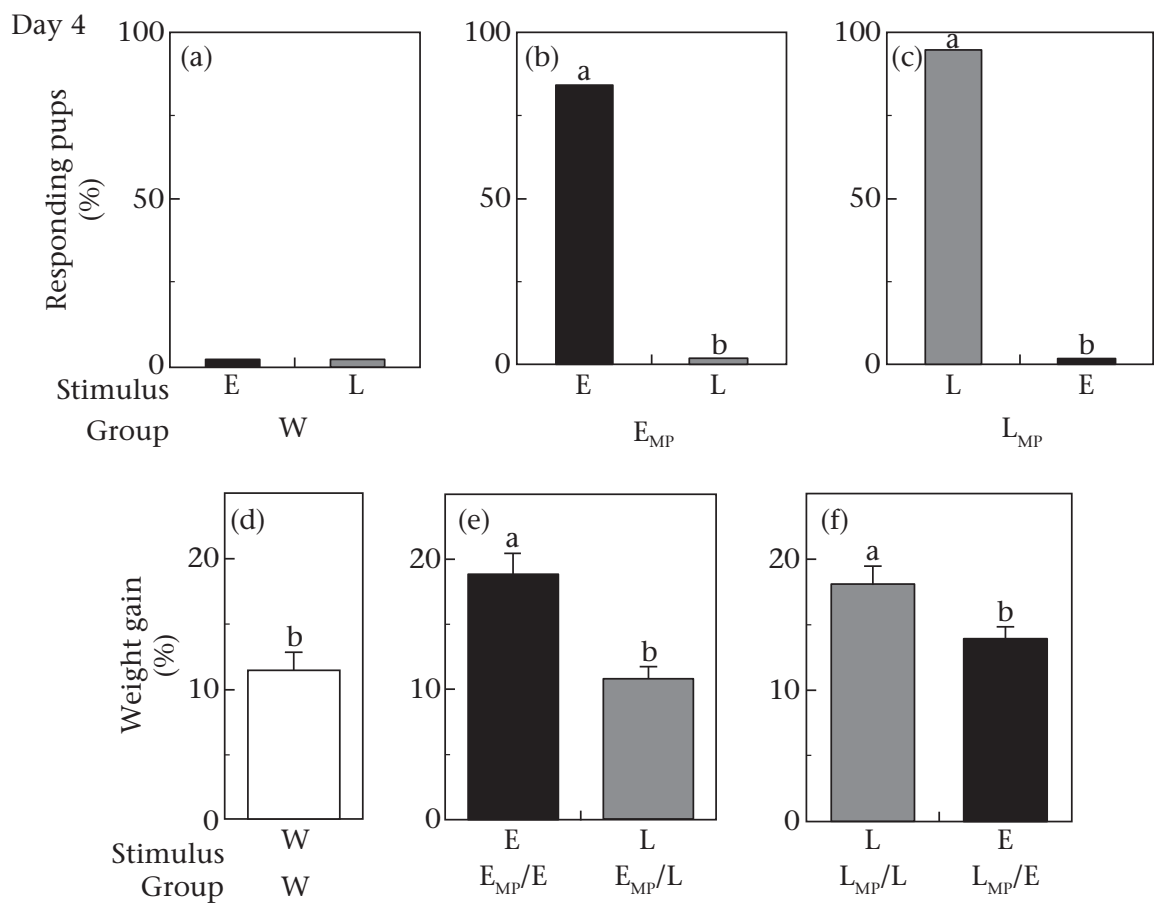

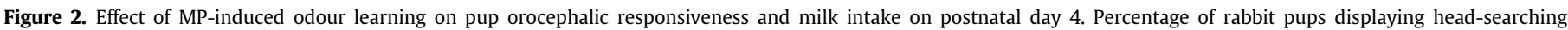

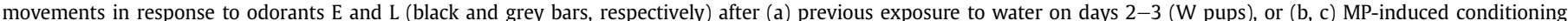

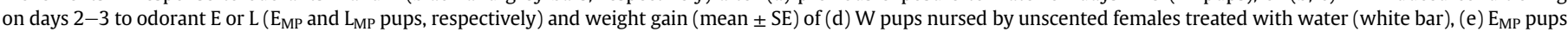

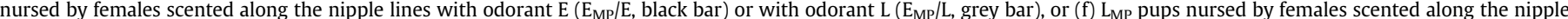

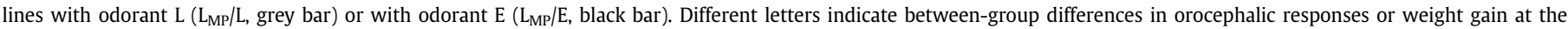
$P<0.05$ level.

Day 5
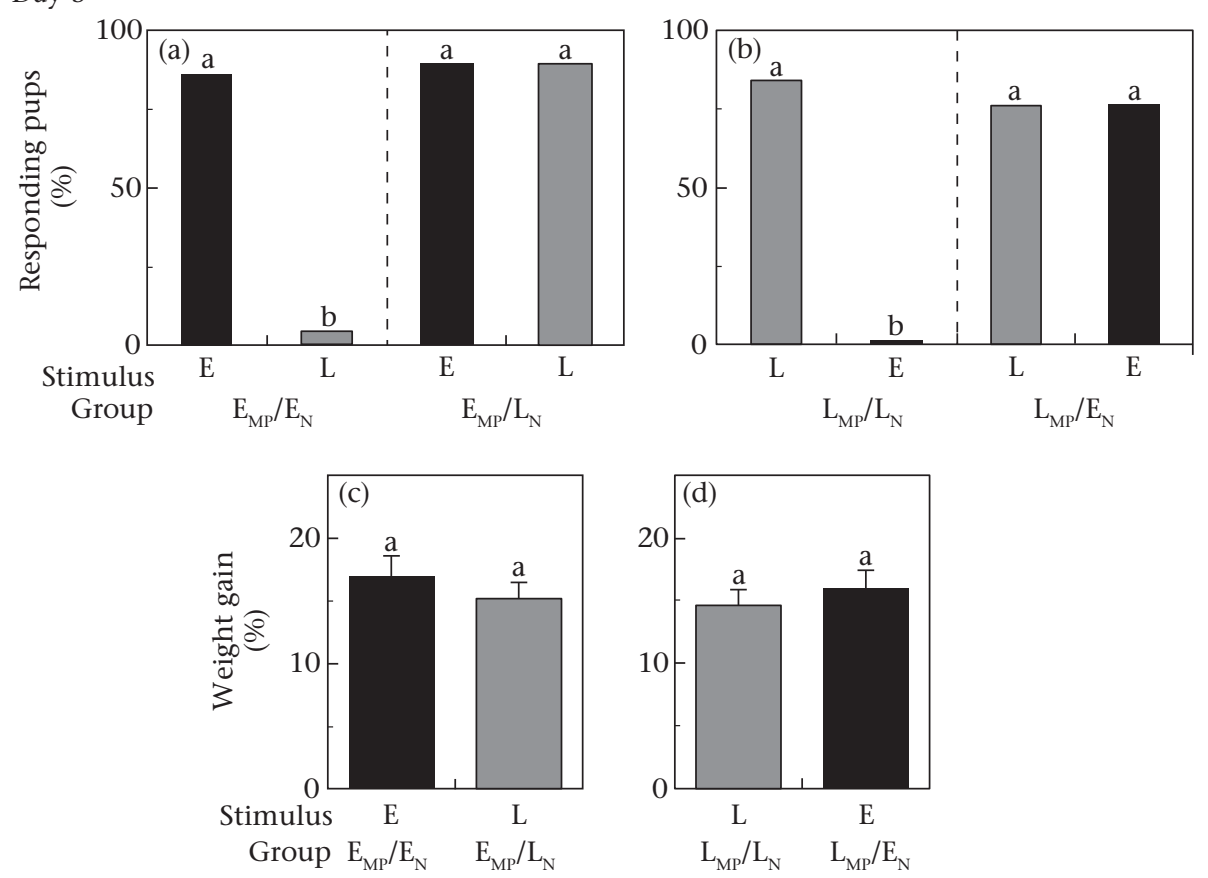

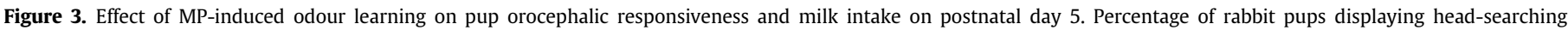

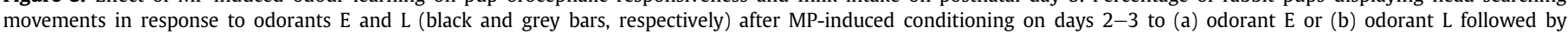

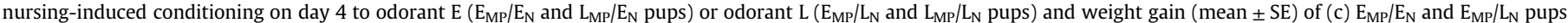

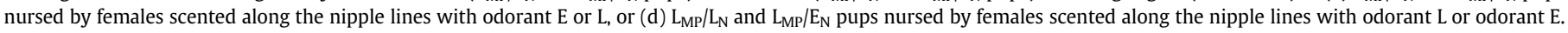
Different letters indicate between-group differences for orocephalic responsiveness or weight gain at the $P<0.05$ level. 
$\mathrm{OR}=1$; Fig. 3b). No differences in weight gain were found between the $\mathrm{E}_{\mathrm{MP}} / \mathrm{E}_{\mathrm{N}}$ versus $\mathrm{E}_{\mathrm{MP}} / \mathrm{L}_{\mathrm{N}}$ pups $(16.97 \pm 1.61 \%$ versus $15.16 \pm 1.29 \%$; Student's $t$ test: $t_{41}=0.87, P>0.05$; Fig. $3 c$ ) and between the $\mathrm{L}_{\mathrm{MP}} / \mathrm{L}_{\mathrm{N}}$ versus $\mathrm{L}_{\mathrm{MP}} / \mathrm{E}_{\mathrm{N}}$ pups $(14.61 \pm 1.28 \%$ versus $15.99 \pm 1.41 \%$; Student's $t$ test: $t_{36}=0.72, P>0.05$; Fig. $3 d$ ), contrary to the results of day 4 . Thus, efficient odour learning induced by nursing happened on postnatal day 4. Moreover, pups exposed on day 5 to a female scented with an odorant different from the odorant they had previously learned by coupling with the MP responded still to the first and also to the second conditioned odorant. After MP-induced learning of $\mathrm{E}$, then nursing-induced learning of $\mathrm{L}, \mathrm{E}_{\mathrm{MP}} / \mathrm{L}_{\mathrm{N}}$ pups performed equivalently in sucking as $E_{M P} / E_{N}$ pups continuously conditioned to the same odorant (and reciprocally for $\mathrm{L}_{\mathrm{MP}} / \mathrm{E}_{\mathrm{N}}$ versus $\mathrm{L}_{\mathrm{MP}} / \mathrm{L}_{\mathrm{N}}$ pups).

\section{EXPERIMENT 2: INFLUENCE OF NURSING-INDUCED ODOUR LEARNING}

\section{Methods}

Here, we evaluated the consequences of odour learning induced by nursing on postnatal days $2-3$ for subsequent milk intake. We hypothesized that these consequences should be at least similar to those induced by MP-induced conditioning, since the MP is only one of the reinforcing agents that occur during nursing (with the act of sucking and the physical and physiological effects of milk intake; Hudson et al., 2002). To that goal, 52 pups were conditioned to odorant $\mathrm{L}$ applied along the nipple lines of the doe's abdomen (group $L_{N}$ ). On day $4,1 \mathrm{~h}$ before being nursed by females scented with either odorant $\mathrm{L}\left(\mathrm{L}_{\mathrm{N}} / \mathrm{L}\right.$ pups, $\left.N=24\right)$ or odorant $\mathrm{E}\left(\mathrm{L}_{\mathrm{N}} / \mathrm{E}\right.$ pups, $N=28$ ), the pups were tested for their orocephalic responsiveness to odorants $\mathrm{L}$ and $\mathrm{E}$; they were also weighed before and after the daily nursing. Measurements of orocephalic responsiveness and weight gain were repeated on day 5 .

\section{Results}

On day $4, \mathrm{~L}_{\mathrm{N}}$ pups responded to odorant $\mathrm{L}$ but not to odorant $\mathrm{E}$ (McNemar's chi-square test: $\chi_{1}^{2}=38.03, P<0.0001$, OR $=21.5$; Fig. 4a). However, $L_{N}$ pups nursed by females scented with odorant $\mathrm{L}$ did not gain more milk than $\mathrm{L}_{\mathrm{N}}$ pups nursed by females bearing odorant $\mathrm{E}\left(\mathrm{L}_{\mathrm{N}} / \mathrm{L}\right.$ versus $\mathrm{L}_{\mathrm{N}} / \mathrm{E}: 15.98 \pm 1.13 \%$ versus $15.47 \pm 1.21 \%$; Student's $t$ test: $t_{50}=0.31, P>0.05$; Fig. $4 \mathrm{~b}$ ). Thus, the selectivity for the odorant that was previously associated with nursing did not appear to influence the sucking performance.

On day 5 , the pups initially conditioned to odorant $\mathrm{L}$ by nursing and then nursed again by females scented with odorant $\mathrm{L}\left(\mathrm{L}_{\mathrm{N}} / \mathrm{L}_{\mathrm{N}}\right.$ pups) displayed searching in response to odorant $\mathrm{L}$ but not to odorant E (McNemar's chi-square test: $\chi^{2}{ }_{1}=20.05, P<0.0001$; Fig. 4c). In contrast, $\mathrm{L}_{\mathrm{N}} / \mathrm{E}_{\mathrm{N}}$ pups conditioned first to odorant $\mathrm{L}$ and then to odorant $\mathrm{E}$ responded to both odorants $\mathrm{L}$ and $\mathrm{E}$ (McNemar's chi-square test: $\chi^{2}{ }_{1}=1.13, P>0.05$, OR $=0.82$; Fig. $4 \mathrm{c}$ ). However, the weight gain was equivalent in $\mathrm{L}_{\mathrm{N}} / \mathrm{L}_{\mathrm{N}}$ and $\mathrm{L}_{\mathrm{N}} / \mathrm{E}_{\mathrm{N}}$ pups respectively nursed by females scented with $\mathrm{L}$ and with $\mathrm{E}(18.05 \pm 1.10 \%$ versus $17.68 \pm 0.92 \%$; Student's $t$ test: $t_{50}=0.26, P>0.05$; Fig. $4 d$ ).

In sum, nursing-induced odour learning influenced orocephalic activation of the pups but, surprisingly, did not have the same positive impact as MP-induced odour conditioning on milk intake (experiment 1). This difference could be due to the location of the conditioned stimulus on the maternal abdomen during the test, namely a wide location rather than a location centred on the nipple lines. To go further, we therefore replicated the assay in the next experiment but we applied the conditioned odorant so that it could work as an effective location cue to the nipples.

\section{EXPERIMENT 3: INFLUENCE OF THE CONDITIONED STIMULUS LOCATION}

\section{Methods}

To determine whether the milk intake was higher when the conditioned odorant was applied directly on rather than around the nipples, 91 pups were conditioned by nursing to odorant $\mathrm{L}$ painted on the doe's mammary lines on postnatal days 2 and 3 (group $\mathrm{L}_{\mathrm{N}}$ ). These pups were then tested for their searching - grasping response to odorants $\mathrm{L}$ and $\mathrm{E}$ on day $4,1 \mathrm{~h}$ before being nursed by their mother scented with odorant L or $\mathrm{E}$ (groups $\mathrm{L}_{\mathrm{N}} / \mathrm{L}$ and $\mathrm{L}_{\mathrm{N}} / \mathrm{E}, N=44$ and 47, respectively). Unlike experiments 1 and 2, the odorants were applied either on the nipples only $\left(\mathrm{L}_{N} / \mathrm{L}: N=24, \mathrm{~L}_{N} / \mathrm{E}: N=24\right.$; Fig. 1b) or on abdominal areas devoid of nipples $\left(\mathrm{L}_{N} / \mathrm{L}: N=20, \mathrm{~L}_{N} / \mathrm{E}\right.$ : $N=23$; Fig. 1c). The pups were weighed before and after the daily nursing on day 4 , and both orocephalic responsiveness and weight gain were also followed on day 5 .

\section{Results}

$\mathrm{L}_{\mathrm{N}}$ pups searched strongly during the presentation of odorant $\mathrm{L}$ but not odorant $\mathrm{E}$ (McNemar's chi-square test: $\chi^{2}{ }_{1}=72.01$, $P<0.0001, \mathrm{OR}=21.5$; Fig. 5a). After nursing, weight gain differences appeared within the conditioned groups according to the nature of the odorant (conditioned versus novel) and its location (nipple versus non-nipple) on the mother's abdomen. Thus, compared to $\mathrm{L}_{\mathrm{N}} / \mathrm{E}$ neonates, $\mathrm{L}_{\mathrm{N}} / \mathrm{L}$ pups ingested more milk when they were nursed by females with their nipples scented with odorant L $(18.24 \pm 1.11 \%$ versus $13.22 \pm 1.10 \%$; Student's $t$ test: $t_{46}=-3.20, P=0.002$; Fig. $\left.5 b\right)$. However, $\mathrm{L}_{\mathrm{N}} / \mathrm{L}$ pups gained less milk than $\mathrm{L}_{\mathrm{N}} / \mathrm{E}$ neonates when they were nursed by females scented with odorant $L$ around the nipples $(13.90 \pm 0.85 \%$ versus $18.09 \pm 1.11 \%$; Student's $t$ test: $t_{41}=2.93, P=0.006$; Fig. $5 \mathrm{c}$ ).

On the follow-up test on day $5, \mathrm{~L}_{\mathrm{N}}$ pups that were nursed $24 \mathrm{~h}$ before by females scented with $\mathrm{L}\left(\mathrm{L}_{\mathrm{N}} / \mathrm{L}_{\mathrm{N}}\right)$ on or around the nipples responded to odorant $\mathrm{L}$ but not to odorant $\mathrm{E}$ (McNemar's chi-square test: $\chi^{2}{ }_{1}>16.06, P<0.0001, \mathrm{OR}=10.5$; Fig. $\left.5 \mathrm{~d}, \mathrm{e}\right)$; conversely, $\mathrm{L}_{\mathrm{N}}$ pups nursed on day 4 by females scented with odorant $E$ on their nipples $\left(\mathrm{L}_{\mathrm{N}} / \mathrm{E}_{\mathrm{N}}\right)$ responded both and similarly to odorants $\mathrm{L}$ and $\mathrm{E}$ (McNemar's chi-square test: $\chi^{2}{ }_{1}=0, P>0.05$, OR $=1.05$; Fig. $5 \mathrm{~d}$ ). However, $\mathrm{L}_{\mathrm{N}} / \mathrm{E}_{\mathrm{N}}$ pups responded more to odorant $\mathrm{L}$ than to odorant $\mathrm{E}$ after exposure to odorant $\mathrm{E}$ around the nipples during the day 4 nursing-induced conditioning (McNemar's chi-square test: $\chi^{2}{ }_{1}=13.07, P<0.0001, \mathrm{OR}=4.75$; Fig. 5e). Regarding weight gain, neither the odorants nor their location on the doe's abdomen during nursing had an influence on sucking success. Thus, in contrast to the results noted on day $4, \mathrm{~L}_{\mathrm{N}} / \mathrm{L}_{\mathrm{N}}$ pups ingested as much milk as $\mathrm{L}_{\mathrm{N}} / \mathrm{E}_{\mathrm{N}}$ pups when they were nursed by females scented on $\left(18.49 \pm 1.07 \%\right.$ versus $15.44 \pm 1.25 \%$; Student's $t$ test: $t_{46}=-1.85$, $P>0.05$; Fig. 5f) or around the nipples $(15.73 \pm 1.48$ versus $17.31 \pm 0.88 \%$; Student's $t$ test: $t_{41}=0.95, P>0.05$; Fig. $5 g$ ).

To sum up, after nursing-induced odour conditioning, the location of the conditioned odorant on or around the nipples of the lactating females constituted an important factor for neonatal sucking performance, at least on the day just after the initial conditioning (i.e. on day 4 here).

\section{DISCUSSION}

The present results confirm that, in newborn rabbits, in addition to its releasing function of sucking-related movements involved in locating and orally seizing of maternal nipples (Coureaud, 2001; Coureaud et al., 2007; Moncomble et al., 2005; Schaal et al., 2003), the MP functions also as an unconditioned stimulus that 

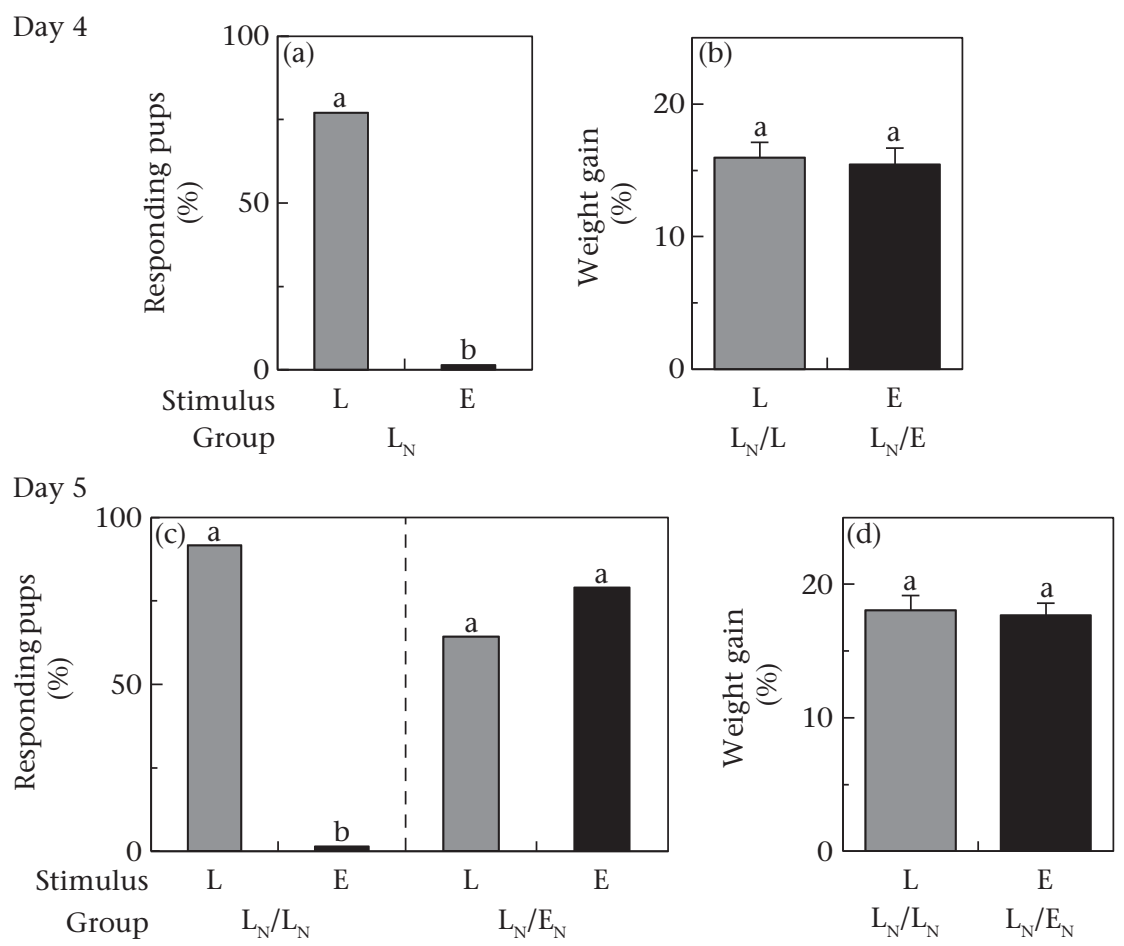

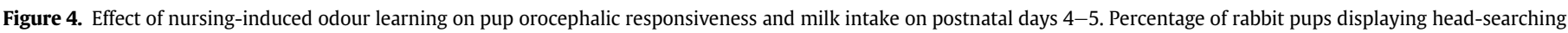

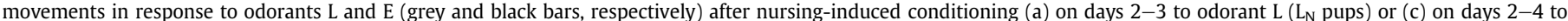

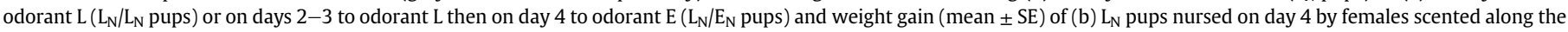

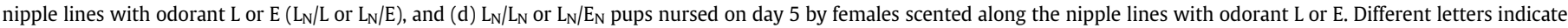
between-group differences for orocephalic responsiveness or weight gain at the $P<0.05$ level.

promotes the rapid acquisition of any associated odour stimulus, be it a single odorant as here (see also Charra et al., 2013; Coureaud, Languille, et al., 2009; Coureaud, Moncomble, et al., 2006; Coureaud et al., 2014) or a more or less complex mixture of odorants (Coureaud, Hamdani, et al., 2009; Coureaud, Thomas-Danguin, et al., 2008; Coureaud et al., 2014; Romagny et al., 2015; Sinding et al., 2013, 2011). Nevertheless, the present study clearly goes further concerning this reinforcing action of the MP by providing several new findings related to its adaptive effect on neonatal feeding.

\section{MP-induced Odour Learning Favours Neonatal Sucking Performance}

In the present conditions, both odorants $\mathrm{E}$ and $\mathrm{L}$, which first were behaviourally inactive, became efficient at triggering suckingrelated head-searching movements in neonates after pairing them with the MP. After this conditioning, the odorant became a cue capable of regulating sucking in pups (experiment 1 ). Indeed, pups conditioned to odorant $\mathrm{E}$ with the MP ( $\mathrm{E}_{\mathrm{MP}}$ pups) and then exposed to females odorized with odorant E showed a higher postnursing weight gain than $E_{M P}$ pups exposed to females odorized with odorant L or than control pups exposed only to water on the female's abdomen. Similar results were obtained with odorant L. One may note that the pups were weighed after the urination that occurs normally in the nest right after nursing. Therefore, the mass of milk consumed was certainly underestimated. Hence, the importance of odour learning on sucking performance might be greater than shown by the present data. Facilitating milk intake by exposure to a previously conditioned odorant appears generalizable across odorants. In both cases (i.e. in $\mathrm{E}_{\mathrm{MP}}$ and $\mathrm{L}_{\mathrm{MP}}$ groups), the learned odorant improved the pups' weight gain after nursing as compared to the weight gain of control (water-exposed) pups and of pups conditioned to odorant $\mathrm{E}$ or $\mathrm{L}$ but nursed with the novel odorant. Novel odorants $\mathrm{E}$ and $\mathrm{L}$ encountered for the first time while nursing were therefore as behaviourally neutral as water. Conversely, rabbit pups selectively attributed a positive value to these odorants after conditioning. The pups' perception of these artificial odorants on the lactating female's abdomen happened in addition to, and not at the expense of, other biologically produced stimuli. Thus, the absence of postnursing weight gain differences between pups exposed to control conditions (water) and pups exposed to novel odorants may be attributable to signals naturally emitted by any lactating rabbit females and whose detection is not impeded by the addition of artificial odorants. When a conditioned stimulus is perceived in addition to the MP, it would then have an additive effect so that both predisposed and learned signals may be synergistic. This is in agreement with previous findings suggesting that rabbit pups detect distinct kinds of odour cues from the abdomen of a lactating female (Coureaud \& Schaal, 2000; Coureaud, Schaal, Langlois, \& Perrier, 2001; Patris et al., 2008). Further, when exposed to rabbit milk from different females, pups strongly respond to any milk but more to the milk containing dietary compounds to which they were already exposed in utero (Coureaud et al., 2002).

Several nonexclusive processes may favour the higher milk intake that was observed when odour-conditioned pups reencountered the conditioned odour on the female's abdomen: (1) the stronger motivation to find the source of odour previously associated with sucking and milk intake; (2) the faster detection of maternal cues and faster expression of nipple-search behaviour; (3) the faster location and access to the nipples; and (4) more intense sucking actions leading to more efficient milk extraction and/or stimulation of milk ejection. As the odorants learned by coupling with the MP elicited vigorous searching-grasping 

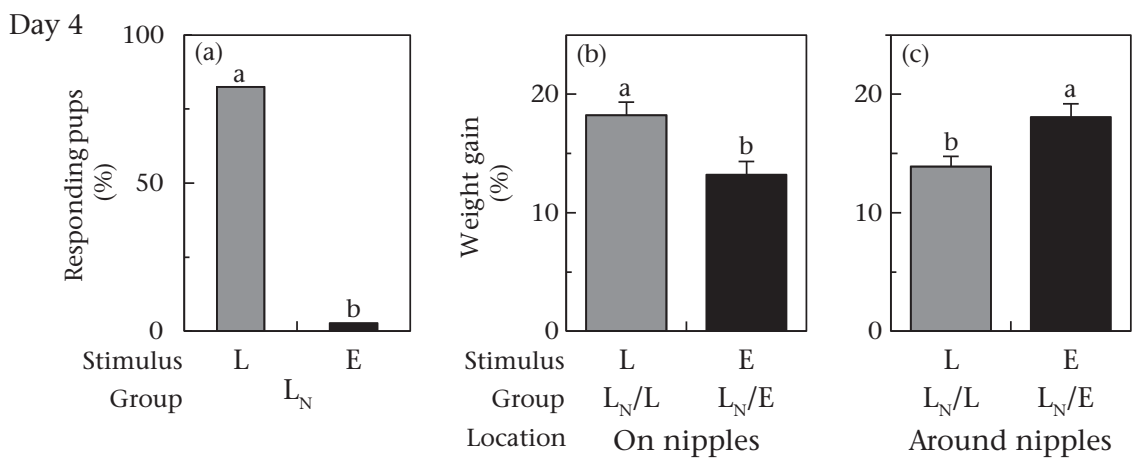

Day 5
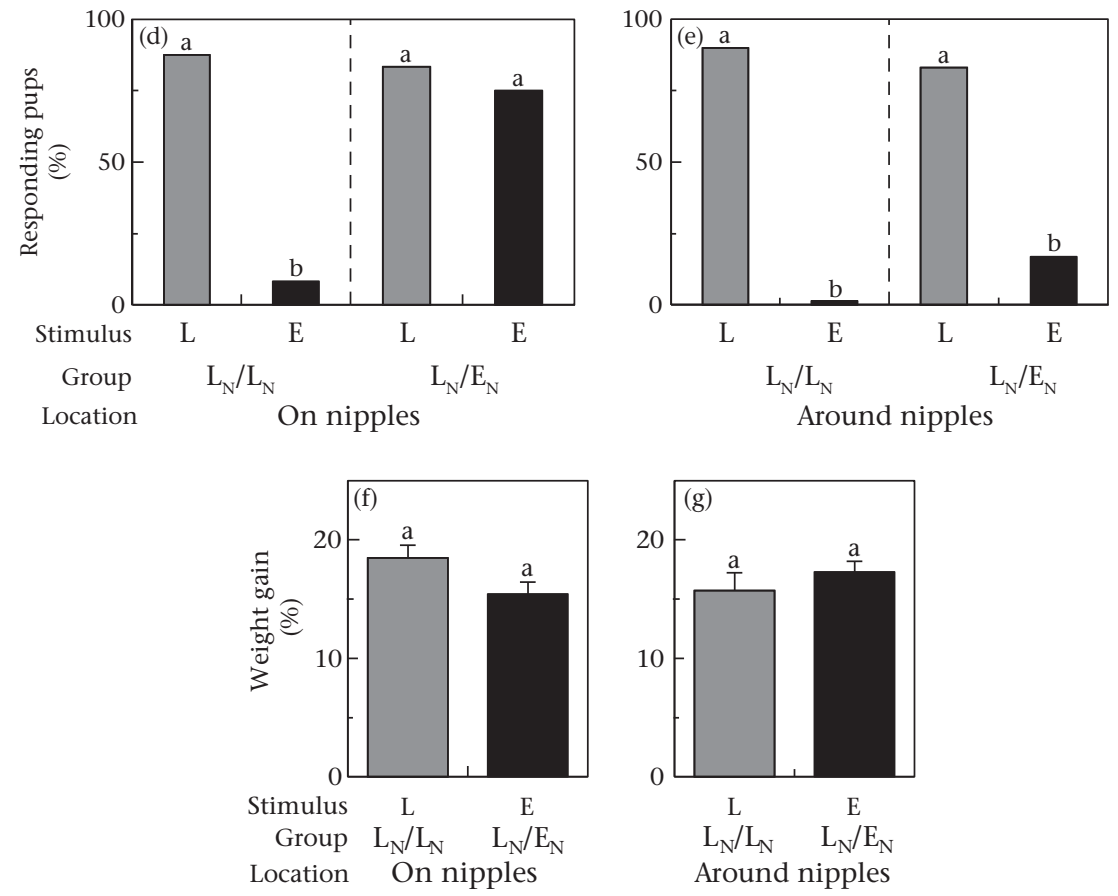

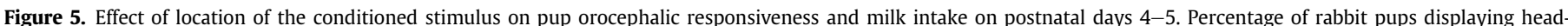

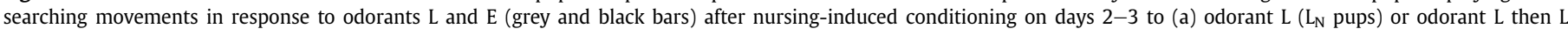

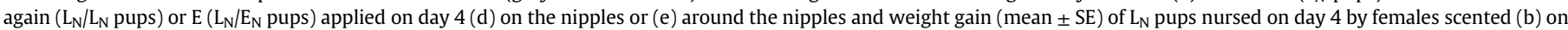

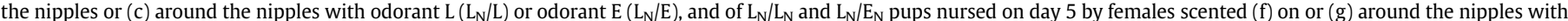
odorant $\mathrm{L}$ or E. Different letters indicate between-group differences for orocephalic responsiveness or weight gain at the $P<0.05$ level.

movements when presented on a glass rod, it is likely that pups display more rapid and more intense nipple-search behaviour when these odorants are detected on the female's abdomen. Such intensity in the nipple-search behaviour of the pups, depending both on the MP and on new odorants learned by pairing with the MP might have direct consequences for lactation. Indeed, during this period (which lasts about 3-4 weeks in wild rabbits, 4-6 in domestic ones, depending on the reproductive state of the female; Broekhuizen, Bouman, \& Went, 1986; Fortun-Lamothe, Prunier, Bolet, \& Lebas, 1999; Lincoln, 1974), the somesthetic stimulations from newborns on the female's abdomen influence the release of oxytocin, which in turn contributes to the evacuation of milk from the doe's mammary glands and the duration of the maternal presence in the nest (González-Mariscal, 2007; González-Mariscal \& Gallegos, 2014). Therefore, the predisposed and conditioned responses of rabbit pups to chemical signals emitted by the mother may be directly linked with the pups' sucking success, on the one hand, and the stimulation of milk synthesis and milk ejection, on the other.
To sum up, an odour that rabbit pups learn on postnatal days 2-3 by association with the MP may be used the day after to optimize milk extraction in the nursing context. In addition to general maturation of sensory-motor abilities occurring during the first few postnatal days, this form of learning may thus improve the pup's skills to locate and grasp the nipples (Cheslock et al., 2000; Drewett, Kendrick, Sanders, \& Trew, 1982; Miller \& Spear, 2008). This seems to be particularly adaptive in the rabbit in which the pups urgently need to suck during the first daily nursing episodes, but in which each newborn swaps nipples during a nursing episode (Coureaud et al., 2000; Hudson \& Distel, 1982). These changes offer a chance for all littermates to locate the nipples and suck, in a context of strong competition within the litter (which usually contains six to eight pups in domestic rabbits). The MP-induced odour learning may improve this capability to rapidly locate and orally seize different nipples several times during a nursing bout, among other parameters that affect the sucking success such as the position of the pups in the litter (Bautista, Mendoza-Degante, Coureaud, Martínez-Gómez, \& Hudson, 2005; García-Torres, 
Hudson, Castelan, Martínez-Gómez, \& Bautista, 2015). These consequences of odour signals emitted from the mammary gland for neonatal learning and milk intake remain to be explored in other species. To date, some results hint at the existence of mammary chemosignals in other mammals (Schaal, 2014; Schaal \& Al Aïn, 2014; Wyatt, 2015). However, as the pheromone concept is a specific suite of phenomena, the demonstration and designation as 'pheromone' of such chemosignals requires chemical isolation and systematic testing of the properties of potential candidate components against those of milk or mammary secretions.

\section{Effect of MP- versus Nursing-induced Odour Learning}

As the MP promotes odour learning and influences ensuing sucking performance in pups, it was possible to compare this effect with the odour learning induced by nursing, i.e. by the natural situation in which the MP is detected among other chemostimuli. Whereas nursing-induced odour conditioning influenced pup orocephalic responses, it did not influence sucking performance when the learned odorant was indiscriminately applied on the maternal abdomen (Experiment 2). This unexpected result could not be caused by an incapacity of the pups to assign saliency to the learned odorant among the other odorants carried on the mother's abdomen, as MP-induced odour conditioning had a positive effect on the weight gain in the same conditions of odorization of the female (Experiment 1). Thus, we thought that the location of the conditioned stimulus (CS) on the mother's abdomen could directly influence the pups' ability to locate nipples. Indeed, as pups may rely on the CS as a guidance cue to the nipples they would then misdirect energy through searching movements on areas not directly related to milk delivery. This assumption was confirmed in Experiment 3: pups conditioned to odorant L during the day 3 nursing gained less milk on day 4 from females scented with odorant $\mathrm{L}$ at a distance from the nipples than from females scented with odorant L on the nipples. This result suggests that pups primarily use the new CS to find the nipples rather than signals that are naturally emitted by the females. Distributing this new CS at some distance from the nipples seems to disorient the pups and reduce their access to the nipples.

Importantly, after nursing-induced conditioning, the conditioned odour became able to cue searching and sucking when it was applied on the nipples: $L_{N}$ pups indeed showed a higher weight gain when exposed to females scented with odorant $L$ than when exposed to females scented with odorant E (Experiment 3). Clearly, the odour information that rabbit pups learned on days 2-3 during nursing was relied upon the next day to optimize milk intake, suggesting a direct influence of odour conditioning on nipple location, oral seizing and motivation to suck. Nursing-induced odour learning has then a similar effect as MP-induced odour conditioning: regardless of odour learning conditions, $L_{M P}$ and $L_{N}$ pups gained $18 \%$ of weight after nursing by females scented with odorant L. Thus, the reinforcing value of the MP alone compares with that afforded by the whole nursing situation with its multiple reinforcers. This confirms that the MP on its own plays a major role during nursing. It not only triggers nipple-search behaviour (Coureaud et al., 2007; Coureaud, Rödel, et al, 2008; Schaal et al., 2003) but also favours the acquisition of novel odours as cues improving future sucking performance.

One may note, however, that the influence of nursing-induced odour learning on milk intake appears to somehow differ from that of MP-induced odour learning. In the second case, the cuing efficiency of the learned odour does not necessitate an accurate location on the nipples, as its application on the nipple lines as a $2 \mathrm{~cm}$ wide strip encompassing nipple and non-nipple areas is sufficient to improve milk intake. Two explanations can be proposed for this location-independent cue efficiency after MP-induced conditioning. First, an odorant conditioned by pairing with the MP may be assigned a lower positive value than an odorant paired with the whole nursing episode. During nursing, the odour is indeed associated with the MP plus several other reinforcing stimuli (Coureaud, Moncomble, et al., 2006; Hudson et al., 2002; Serra et al., 2009). Thus, when pups encounter the odour cue resulting from MP-induced learning $24 \mathrm{~h}$ before the observed nursing, they might persist in searching for MP or other cues that had already been reinforced during earlier nursing. They might therefore not be disturbed by the conditioned odorant located away from the nipples and might focus their searching movements to areas naturally emitting the MP plus other cues, i.e. the nipples themselves (the nipple epidermis, but not adjacent skin, is highly effective at eliciting pup responsiveness; Moncomble et al., 2005). Second, during MP-induced odour conditioning, the odorant may be assigned a higher positive value, but the odorant + MP mixture may be attributed the highest value as an attractive stimulus. Accordingly, pups should display their searching activity under the female preferentially towards regions carrying this mixture (i.e. the nipples) as opposed to the regions carrying only the odorant.

\section{Influence of Last Odour Conditioning on Milk Intake}

We assessed whether the effects of MP- or nursing-induced odour learning on milk intake differed in terms of persistence over time in rabbit neonates. After controlled conditioning (regardless of procedure) on postnatal days 2-3, the pups still responded by searching movements on day 5 to the odorant encountered during nursing on day 4 . There was one exception, however: after initial learning of odorant $\mathrm{L}$ during nursing on days 2-3 and nursing on day 4 by females scented with odorant $\mathrm{E}$ around their nipples, the responsiveness to odorant $E$ of these $L_{N} / E_{N}$ pups remained low on day 5 (Experiment 3). Thus, the actual responsiveness to an odorant, even after multiple conditionings, seems to depend on the last exposure that occurred the day before and on the location at which the odorant was experienced on the mother's body: the odorant is best learned when painted on the nipples than at a distance from them. This confirms that the reinforcers involved in promoting odour learning during nursing are associated with the nipples and linked with sucking and milk intake (Hudson et al., 2002), and strongly argues in favour of the MP itself as a major reinforcing agent which fully functions on the nipples (Coureaud, Moncomble, et al., 2006).

Newborn rabbits appeared able to learn two distinct odorants met during consecutive conditionings (Experiments 1 and 2, and Experiment 3 with odorant $\mathrm{E}$ added on nipples). After MP-induced as well as after nursing-induced learning of odorant $L$ on days $2-3$, and nursing by females scented with odorant $\mathrm{E}$ on day 4 , both $\mathrm{L}_{\mathrm{MP}} / \mathrm{E}_{\mathrm{N}}$ and $\mathrm{L}_{\mathrm{N}} / \mathrm{E}_{\mathrm{N}}$ pups responded to odorant $\mathrm{E}$ (last acquisition) in addition to odorant $\mathrm{L}$ on day 5 . Convergent results from $\mathrm{E}_{\mathrm{MP}} / \mathrm{L}_{\mathrm{N}}$ pups highlight the generality of consecutive odour learning for the formation of multiple odour cues within very short periods of time. This phenomenon indicates that the most recent learning experience does not interfere with the preceding one, i.e. the newly created odour memory does not erase the memory of the previous odour. The retention of the first odour remains maximal $48 \mathrm{~h}$ after its acquisition despite the occurrence of an intermediate odour learning (see also Coureaud, Moncomble, et al., 2006). Rabbit newborns can thus acquire distinct odours during consecutive pairings with nursing or with the MP alone without retroactive interference.

In terms of sucking efficacy and milk intake, the advantage in weight gain observed on postnatal day 4 after initial (days 2-3) odour learning was balanced on day 5 by the experience that happened during the day 4 nursing. Thus, one could reasonably 
expect that pups that find on the maternal abdomen on day 5 the odorant previously learned on days 2-3 and that re-experienced it during nursing on day 4 (i.e. $\mathrm{E}_{\mathrm{MP}} / \mathrm{E}_{\mathrm{N}}, \mathrm{L}_{\mathrm{MP}} / \mathrm{L}_{\mathrm{N}}$ and $\mathrm{L}_{\mathrm{N}} / \mathrm{L}_{\mathrm{N}}$ pups) should show maximal weight gain. Actually, pups nursed on day 4 by a female scented with a distinct odorant compared to days 2 and 3 (i.e. $\mathrm{E}_{\mathrm{MP}} / \mathrm{L}_{\mathrm{N}}, \mathrm{L}_{\mathrm{MP}} / \mathrm{E}_{\mathrm{N}}$ and $\mathrm{L}_{\mathrm{N}} / \mathrm{E}_{\mathrm{N}}$ pups), and that re-encountered this novel odorant on day 5 , had a strong weight gain too; their weight gain was even similar to that of pups continuously exposed to the same odorant during nursing from days 2 to 5 . Therefore, after consecutive conditioning to two distinct odorants, the pups appear to respond to the most recently conditioned odorant during nursing, although they do not forget the previously conditioned odorant. Thus, the most recent conditioning episode does not erase the previous one, and it seems that the last CS becomes, as the MP itself, an efficient cue involved in the location of the milk source.

In the case of nursing-induced odour learning on days $2-3$, the sucking performance of $\mathrm{L}_{\mathrm{N}} / \mathrm{L}$ pups was impaired on day 4 when the CS was painted around the nipples (experiment 3 ). When these pups were re-exposed to the same odorant on day 5, again around the nipples, this negative effect disappeared. This may be interpreted in terms of reliability of the odour cue: when the CS does not help in finding the nipples on one day, the pups may use other odour stimuli on the next day. They may then focus on the MP or on other kinds of cues. Cues acquired during the last sucking experience will orient their subsequent behaviour during the actual interaction with the mother.

Taken together, the present results suggest that the sucking performance of newborn rabbits is partially influenced by maternal odours experienced during previous nursing episodes. Rabbit pups may refer to the MP and to odour cues previously learned in association with the MP (and with the nursing as a whole) to locate and grasp nipples. The location of the CS on the maternal abdomen modulates this learning effect and, hence, the biological significance acquired by the CS. When a stimulus learned on a given day does not improve the sucking performance the day after, its value decreases in the nursing context and pups respond then to alternative odour signals emitted from the nipples (e.g. to the MP). Such behavioural plasticity from one day to another can support adaptive responses. Indeed, when odour cues continuously occur for several days on the female's abdomen, they can improve the motivation and orientation of the pups under the female. Conversely, tracking only a single odorant, previously learned, can be detrimental to sucking performance in the absence of olfactory continuity across nursing episodes. The olfactory signature of rabbit females may fluctuate over time as a function of her interaction with the environment over the day (e.g. diet; Bilkó et al., 1994; Coureaud et al., 2002). Owing to this olfactory variability and the day-long interval between two nursing episodes, the probability is high that rabbit pups face fluctuations in their mother's olfactory signature so that odours learned on previous days are not necessarily all valid as cues to the nipples. The strong and permanent behavioural activity of the MP during the first 10 postnatal days (Coureaud, Rödel, et al., 2008) may then ensure chemical continuity across nursing episodes. Hence, the predisposed signal and multiple learned odour cues interact to ensure efficient sucking performance in rabbit neonates.

\section{Acknowledgments}

We gratefully thank Valérie Saint-Giorgio, Nicolas Malaty and Florent Costilhes for taking care of the animals in the Centre de Zootechnie de l'Université de Bourgogne (Dijon), and Thierry Thomas-Danguin for contribution to statistical analyses. This work was supported by grants from the Regional Council of Burgundy and Centre National de la Recherche Scientifique.

\section{References}

Al Aïn, S., Belin, L., Schaal, B., \& Patris, B. (2013). How does a newly born mouse get to the nipple? Odor substrates eliciting first nipple grasping and sucking responses. Developmental Psychobiology, 55, 888-901.

Allingham, K., Brennan, P. A., Distel, H., \& Hudson, R. (1999). Expression of c-fos in the main olfactory bulb of neonatal rabbits in response to garlic as a novel and conditioned odour. Behavioural Brain Research, 104, 157-167.

Bautista, A., Mendoza-Degante, M., Coureaud, G., Martínez-Gómez, M., \& Hudson, R. (2005). Scramble competition in newborn domestic rabbits for an unusually restricted milk supply. Animal Behaviour, 70, 1011-1021.

Beauchamp, G. K., Doty, R. L., Moulton, D. G., \& Mugford, R. A. (1976). The pheromone concept in mammalian chemical communication: a critique. In R. L. Doty (Ed.), Mammalian olfaction, reproductive processes and behavior (pp. 143-160). New York, NY: Academic Press.

Bilkó, A., Altbäcker, V., \& Hudson, R. (1994). Transmission of food preference in the rabbit: the means of information transfer. Physiology \& Behavior, 56, 907-912.

Blum, J. W., \& Hammon, H. (2000). Colostrum effects on the gastrointestinal tract, and on nutritional, endocrine and metabolic parameters in neonatal calves. Livestock Production Science, 66, 151-159.

Brake, S. C. (1981). Suckling infant rats learn a preference for a novel olfactory stimulus paired with milk delivery. Science, 211, 506-508.

Broekhuizen, S., Bouman, E., \& Went, W. (1986). Variation in timing of nursing in the Brown Hare (Lepus europaeus) and the European Rabbit (Oryctolagus cuniculus). Mammal Review, 16, 139-144.

Charra, R., Datiche, F., Gigot, V., Schaal, B., \& Coureaud, G. (2013). Pheromoneinduced odor learning modifies Fos expression in the newborn rabbit brain Behavioural Brain Research, 237, 129-140.

Cheslock, S. J., Varlinskaya, E. I., Petrov, E. S., \& Spear, N. E. (2000). Rapid and robust olfactory conditioning with milk before suckling experience: promotion of nipple attachment in the newborn rat. Behavioral Neuroscience, 114, 484-495.

Coureaud, G. (2001). La régulation olfactive de la prise lactée chez le lapereau: caractérisation éthologique et chimique d'un signal phéromonal [Olfactory regulation of sucking in newborn rabbit: Ethological and chemical characterisation of a pheromonal signal] (Doctoral dissertation). Paris, France: Université de Paris 13.

Coureaud, G., Fortun-Lamothe, L., Langlois, D., \& Schaal, B. (2007). The reactivity of neonatal rabbits to the mammary pheromone as a probe for viability. Animal, 1 , 1026-1032.

Coureaud, G., Hamdani, Y., Schaal, B., \& Thomas-Danguin, T. (2009). Elemental and configural processing of odour mixtures in the newborn rabbit. The Journal of Experimental Biology, 212, 2525-2531.

Coureaud, G., Langlois, D., Perrier, G., \& Schaal, B. (2003). A single key-odorant accounts for the pheromonal effect of rabbit milk: further test of the mammary pheromone's activity against a wide sample of volatiles from milk. Chemoecology, 13, 187-192.

Coureaud, G., Langlois, D., Perrier, G., \& Schaal, B. (2006). Convergent changes in the maternal emission and pup reception of the rabbit mammary pheromone. Chemoecology, 16, 169-174.

Coureaud, G., Languille, S., Schaal, B., \& Hars, B. (2009). Pheromone-induced olfactory memory in newborn rabbits: involvement of consolidation and reconsolidation processes. Learning and Memory, 16, 470-473.

Coureaud, G., Moncomble, A. S., Montigny, D., Dewas, M., Perrier, G., \& Schaal, B. (2006). A pheromone that rapidly promotes learning in the newborn. Current Biology, 16, 1956-1961.

Coureaud, G., Rödel, H. G., Kurz, C. A., \& Schaal, B. (2008). The responsiveness of young rabbits to the mammary pheromone: developmental course in domestic and wild pups. Chemoecology, 18, 53-59.

Coureaud, G., \& Schaal, B. (2000). Attraction of newborn rabbits to abdominal odors of adult conspecifics differing in sex and physiological state. Developmental Psychobiology, 36, 271-281.

Coureaud, G., Schaal, B., Coudert, P., Rideaud, P., Fortun-Lamothe, L., Hudson, R. et al. (2000). Immediate postnatal sucking in the rabbit: its influence on pup survival and growth. Reproduction Nutrition Development, 40, 19-32.

Coureaud, G., Schaal, B., Hudson, R., Orgeur, P., \& Coudert, P. (2002). Transnatal olfactory continuity in the rabbit: behavioral evidence and short-term consequence of its disruption. Developmental Psychobiology, 40, 372-390.

Coureaud, G., Schaal, B., Langlois, D., \& Perrier, G. (2001). Orientation response of newborn rabbits to odours of lactating females: relative effectiveness of surface and milk cues. Animal Behaviour, 61, 153-162.

Coureaud, G., Thomas-Danguin, T., Le Berre, E., \& Schaal, B. (2008). Perception of odor blending mixtures in the newborn rabbit. Physiology \& Behavior, 95, 194-199.

Coureaud, G., Thomas-Danguin, T., Wilson, D. A., \& Ferreira, G. (2014). Neonata representation of odour objects: distinct memories of the whole and its parts. Proceedings of the Royal Society B: Biological Sciences, 281, 20133319.

Delaunay-El Allam, M., Marlier, L., \& Schaal, B. (2006). Learning at the breast: preference formation for an artificial scent and its attraction against the odor of maternal milk. Infant Behavior and Development, 29, 308-321.

Drewett, R. F., Kendrick, K. M., Sanders, D. J., \& Trew, A. M. (1982). A quantitative analysis of the feeding behavior of suckling rabbits. Developmental Psychobiology, 15, 25-32.

Fillion, T. J., \& Blass, E. M. (1986). Infantile experience with suckling odors determines adult sexual behavior in male rats. Science, 231, 729-731. 
Fortun-Lamothe, L., Prunier, A., Bolet, G., \& Lebas, F. (1999). Physiological mechanisms involved in the effects of concurrent pregnancy and lactation on foetal growth and mortality in the rabbit. Livestock Production Science, 60, 229-241.

Galef, B. G., \& Henderson, P. W. (1972). Mother's milk: a determinant of the feeding preferences of weaning rat pups. The Journal of Comparative and Physiological Psychology, 78, 213-219.

García-Torres, E., Hudson, R., Castelan, F., Martínez-Gómez, M., \& Bautista, A. (2015). Differential metabolism of brown adipose tissue in newborn rabbits in relation to position in the litter huddle. Journal of Thermal Biology, 51, 33-41.

González-Mariscal, G. (2007). Mother rabbits and their offspring: timing is everything. Developmental Psychobiology, 49, 71-76.

González-Mariscal, G., \& Gallegos, J. A. (2014). The maintenance and termination of maternal behavior in rabbits: involvement of suckling and progesterone. Physiology \& Behavior, 124, 72-76.

Goursaud, A. P., \& Nowak, R. (1999). Colostrum mediates the development of mother preference by newborn lambs. Physiology \& Behavior, 67, 49-56.

Hepper, P. G., \& Wells, D. L. (2006). Perinatal olfactory learning in the domestic dog. Chemical Senses, 31, 207-212.

Hudson, R. (1985). Do newborn rabbits learn the odor stimuli releasing nipplesearch behavior? Developmental Psychobiology, 18, 575-585.

Hudson, R., \& Distel, H. (1982). The pattern of behaviour of rabbit pups in the nest. Behaviour, 79, 255-271.

Hudson, R., \& Distel, H. (1983). Nipple localisation by newborn rabbits: behavioural evidence for pheromonal guidance. Behaviour, 85, 260-275.

Hudson, R., Labra-Cardero, D., \& Mendoza-Soylovna, A. (2002). Sucking, not milk, is important for the rapid learning of nipple-search odors in newborn rabbits. Developmental Psychobiology, 41, 226-235.

Ivanitskii, A. M. (1958). The ontogenic development of conditioned reflex activity in rabbits. Bulletin of Experimental Biology and Medicine, 46, 786-789.

Johanson, I. B., \& Hall, W. G. (1979). Appetitive learning in 1-day-old rat pups. Science, 205, 419-421.

Kindermann, U., Gervais, R., \& Hudson, R. (1991). Rapid odor conditioning in newborn rabbits: amnesic effect of hypothermia. Physiology \& Behavior, 50, 457-460.

Larson, M. A., \& Stein, B. E. (1984). The use of tactile and olfactory cues in neonatal orientation and localization of the nipple. Developmental Psychobiology, 17, 423-436.

Lincoln, D. W. (1974). Suckling: a time-constant in the nursing behaviour of the rabbit. Physiology \& Behavior, 13, 711-714.

Miller, S. S., \& Spear, N. E. (2008). Olfactory learning in the rat neonate soon after birth. Developmental Psychobiology, 50, 554-565.

Moncomble, A. S., Coureaud, G., Quennedey, B., Langlois, D., Perrier, G., \& Schaal, B. (2005). The mammary pheromone of the rabbit: from where does it come? Animal Behaviour, 69, 29-38.

Montigny, D., Coureaud, G., \& Schaal, B. (2006). Rabbit pup response to the mammary pheromone: from automatism to prandial control. Physiology \& Behavior, $89,742-749$
Patris, B., Perrier, G., Schaal, B., \& Coureaud, G. (2008). Early development of filial preferences in the rabbit: implications of nursing- and pheromone-induced odour learning? Animal Behaviour, 76, 305-314.

Pedersen, P. E., Williams, C. L., \& Blass, E. M. (1982). Activation and odor conditioning of suckling behavior in 3-day-old albino rats. Journal of Experimental Psychology: Animal Behavior Processes, 8, 329-341.

Raihani, G., Gonzalez, D., Arteaga, L., \& Hudson, R. (2009). Olfactory guidance of nipple attachment and suckling in kittens of the domestic cat: inborn and learned responses. Developmental Psychobiology, 51, 662-671.

Romagny, S., Thomas-Danguin, T., \& Coureaud, G. (2015). Configural processing of odor mixture: does the learning of elements prevent the perception of configuration in the newborn rabbit? Physiology \& Behavior, 142, 161-169.

Schaal, B. (2010). Mammary odor cues and pheromones: mammalian infantdirected communication about maternal state, mammae, and milk. Vitamins and Hormones, 83, 83-136.

Schaal, B. (2014). Pheromones for newborns. In C. Mucignat-Caretta (Ed.), Neurobiology of chemical communication (pp. 483-515). Boca Raton, FL: CRC Press.

Schaal, B., \& Al Aïn, S. (2014). Chemical signals 'selected for' newborns in mammals. Animal Behaviour, 97, 289-299.

Schaal, B., Coureaud, G., Langlois, D., Ginies, C., Semon, E., \& Perrier, G. (2003). Chemical and behavioural characterization of the rabbit mammary pheromone. Nature, 424, 68-72.

Serra, J., Ferreira, G., Mirabito, L., Levy, F., \& Nowak, R. (2009). Post-oral and perioral stimulations during nursing enhance appetitive olfactory memory in neonatal rabbits. Chemical Senses, 34, 405-413.

Sinding, C., Thomas-Danguin, T., Chambault, A., Beno, N., Dosne, T., Chabanet, C., et al. (2013). Rabbit neonates and human adults perceive a blending 6component odor mixture in a comparable manner. PLoS One, 8, e53534.

Sinding, C., Thomas-Danguin, T., Crepeaux, G., Schaal, B., \& Coureaud, G. (2011). Experience influences elemental and configural perception of certain binary odour mixtures in newborn rabbits. The Journal of Experimental Biology, 214, $4171-4178$.

Teicher, M. H., \& Blass, E. M. (1977). First suckling response of the newborn albino rat: the roles of olfaction and amniotic fluid. Science, 198, 635-636.

Varendi, H., Porter, R. H., \& Winberg, J. (1994). Does the newborn baby find the nipple by smell? Lancet, 344, 989-990.

Verga, M., Canali, E., Pizzi, F., \& Crimella, C. (1986). Induced reactions in young rabbits of dams of different parity and reared on two different nursing schedules. Applied Animal Behaviour Science, 16, 285-293.

Wyatt, T. D. (2015). The search for human pheromones: the lost decades and the necessity of returning to first principles. Proceedings of the Royal Society B: Biological Sciences, 282.

Xu, R. J. (1996). Development of the newborn GI tract and its relation to colostrum/ milk intake: a review. Reproduction, Fertility and Development, 8, 35-48.

Zarrow, M. X., Denenberg, V. H., \& Anderson, C. O. (1965). Rabbit: frequency of suckling in the pup. Science, 150, 1835-1836. 